\title{
AN INTERNET-BASED MANAGEMENT INFORMATION SYSTEM FOR THE LOGISTICS OF HIGHWAY CONSTRUCTION AND MAINTENANCE VEHICLES
}

\author{
Fu-Yih Shih', Ph. D., Yueh Liang' ${ }^{2}$ Ph. D., Chih-Shiung Wu ${ }^{3}$, Chen-Chyi Lin ${ }^{4}$ \\ ${ }^{1}$ Professor of Information Technology, Leader University, Tainan, Taiwan, \\ fuyih@mail.leader.edu.tw \\ ${ }^{2}$ Director general, ${ }^{3}$ Acting Director of MIS, ${ }^{4}$ Director of Equipments and Supplies Dep., \\ Highway Bureau, Ministry of Transportation and Communication, ROC
}

\begin{abstract}
An Internet-based management information system for the logistics of highway construction and maintenance vehicles has been designed and implemented by using Microsoft Visual FoxPro. This presented system is not only useful for the logistics of highway construction and maintenance vehicles but also helpful for the prevention of scandal intentions and activities.
\end{abstract}

Keywords: logistics, management information system, database management

\section{INTRODUCTION}

The work scope of the Highway Bureau of the Ministry of Transportation and Communication in Taiwan includes the planning, design, construction and maintenance of Taiwan Highway, and the supervision of motor vehicles and drivers. With totally around 8,000 employees and US\$3 Billion budget per year, the Taiwan Highway Bureau handles highway with $20,000 \mathrm{Km}$ distance and supervises 13.5 million vehicles and 14.6 million drivers.

For the purpose of construction and maintenance of Taiwan highway, there are totally thirteen engineering divisions being allocated around this country. The highway construction and maintenance vehicles including crawler excavator, vibratory excavator, finishing machine, loaders, rollers, motor grader, trailer, tractor, fork lifter, bituminous paving car, dumping truck, bridge inspection truck, water sprinkler, sweepers, etc., are used by the engineering divisions. The total number of various kind of vehicles owned by the Taiwan Highway Bureau ends up with something around fourteen hundreds.

Conventionally, the Equipments and Supplies Department of the Taiwan Highway Bureau has been responsible for the logistics and supervisions of these vehicles based on the reports of the thirteen engineering divisions allocated around Taiwan. Because not only the number of categories of the vehicles is more than 25 , but also the concerned information, such as brand, model, and various specifications of the vehicles, is so many, especially, the total 1,400 vehicles are distributed in the 13 engineering divisions allocated around this country, we can imagine that it will be so difficult to handle the logistics and supervisions suppose there is no computerized management information system to apply.

Due to the background story as described above, a management information system for the logistics and supervisions of highway construction and maintenance vehicles has been designed and implemented by using the Microsoft Visual FoxPro [1].

Fundamentally, each construction or maintenance vehicle owned by the Taiwan Highway Bureau, with all its necessary information including the vehicle specifications and photograph, has been created as part of the database of this management information system for the convenience of supervision and logistics. For the purpose of supervision, the dynamic management functions have been also implemented into this system. The Internet mechanism incorporated in this system is used to update and transmit both the static and dynamic data from the 13 engineering divisions distributed all over the country to the main office of Taiwan Highway Bureau in Taipei.

A user-friendly system menu, as shown in Fig. 1 , is designed to make job selections as simple as possible. The macro jobs include maintenance of vehicle static database, maintenance of vehicle dynamic database, vehicle managements based on the static database, vehicle supervisions in accordance with the dynamic database, and database transmission. The photographic zoom-in and zoomout technique is also incorporated into this management information system to make the vehicle recognitions as easy as possible.

The management information system presented in this paper has been proven that it is not only useful for the normal logistics and supervisions of highway construction and maintenance vehicles but 
also helpful for the prevention of scandal intentions and activities.

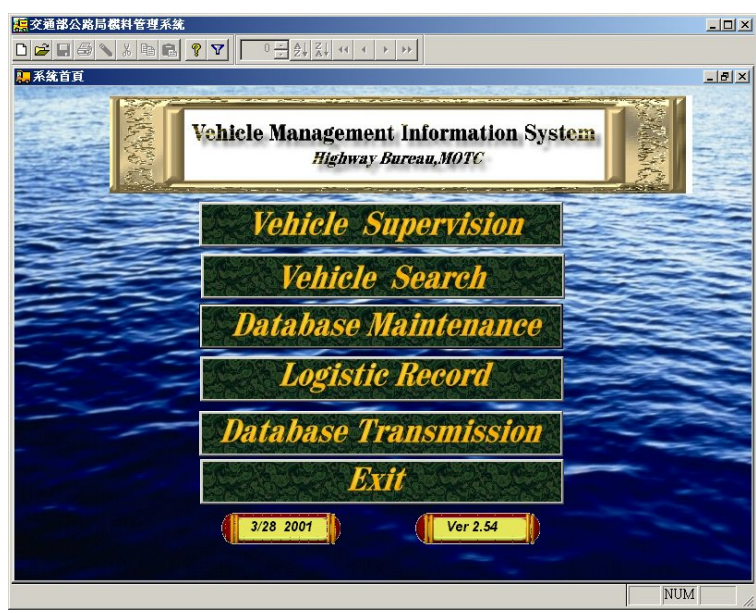

Fig. 1 System Manu

\section{SYSTEM ANALYSIS}

For the purpose of supervision and logistics, the most concerned information of the various kinds of construction and maintenance vehicles include the vehicle categories, the detailed specifications of the vehicles, the corresponding end-users and supervisors of the vehicles, as well as the logistic records of the vehicles.

The other mechanisms including the maintenance of the vehicle database and the transmission of the updated database are the necessary functions of this management information system.

\subsection{Vehicle categories and providers}

The highway construction and maintenance vehicles owned by the Taiwan Highway Bureau include the following categories: crawler excavator, wheel excavator, vibratory roller, rubber roller, bituminous paving car, motor grader, finishing machine, loader, light loader, fork lifter, trailer, tractor, water sprinkler, street sweeper, vacuum sweeper, truck wrecking, bridge inspection truck, air working truck, engineering service truck, dumping truck, heavy truck, light truck, pickup, bus, sedan, and etc.

The vehicle providers or brands of the vehicles mentioned above are as follows: Chevrolet, Chrysler, Ford, Hino, Honda, Isuzu, Mazda, Mitsubishi, Nissan, Toyota, and etc.

The information about the vehicle categories and their providers are important especially for the spare parts procurement. The procurement of the spare parts is the most fundamental work for handling the logistics of the highway construction and maintenance vehicles.

\subsection{Vehicle specifications}

The vehicle specifications and their related information are important especially for the logistics of the vehicles. It consists of the following items: vehicle brand, vehicle model, year of manufacturing, overall length, overall width, overall height, overall weight, chassis loading capacity, available seats, wheelbase, engine number, engine brand, engine model, displacement, number of cylinders, maximum horsepower, maximum torque, cooling system, fuel, transmission, and drive system.

The related information of the vehicles includes: assets serial number, the starting date and the cancellation date, if it is available.

\subsection{Vehicle allocation and logistic records}

For each specific vehicle, its allocation information, e.g. the current end-user and its assigned supervisor, and the historical logistic records are necessary not only for the purpose of logistics but also for the purpose of supervision.

The concerned logistic records of each specific vehicle include: the accumulated maintenance cost, the accumulated fuel consumption, the accumulated mileage, the accumulated service hours, and etc.

\subsection{Vehicle supervision}

In order to optimize the performance of the construction and maintenance vehicles and, by the way, to prevent the scandal intentions and activities, the vehicle management information system should be able to provide some kind of information for the reference and judgment of the vehicle supervisors and the high ranking highway officials.

The information that will be helpful for the supervision of the vehicles can be related to the logistic records. Based on the fundamental logistic records as mentioned above, the value-added information such as the various average values of the maintenance cost, the fuel consumption, the mileage, and the service hours can be calculated and sorted automatically by the management information system.

\subsection{Multimedia and Internet technique linkage}

By considering the normalization of the relational database, and using the object-oriented programming technique, the vehicle photographs can be incorporated into this management information system to make the vehicle identifications more easily.

Because the highway construction and maintenance vehicles, with a total number around 1400, are allocated around Taiwan, in order to keep the logistic database always updated, the Internet 
environment will be quite helpful and cost effective.

\section{SYSTEM DESIGN AND IMPLEMENTATION}

In accordance with the system analysis as described above, an internet-based management information system for the logistics and supervision of the highway construction and maintenance vehicles is designed and implemented by using Microsoft Visual FoxPro.

\subsection{Creation of system database}

The system database consists of the relational tables with fields including the vehicle category, the vehicle provider, the various vehicle specifications that are mentioned in the system analysis section, the end-user, the supervisor, the vehicle photographs, and the logistic records as also mentioned above.

The relational tables of the system database are created by normalization technique and implemented by using the Table Designer and the Database Designer of Microsoft Visual FoxPro.

\subsection{Forms designed by OOP technique}

The object-oriented programming utilities, including the Form Designer supplied by Microsoft Visual FoxPro, are used to design all the forms of this management information system.

The database maintenance form, as shown in Fig.2, is designed for the purpose of updating the system database.

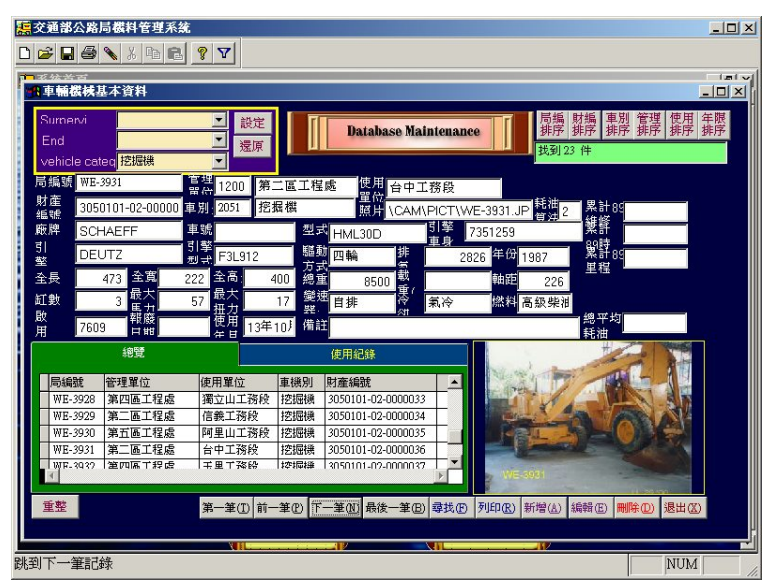

Fig. 2 Database Maintenance Form

The database maintenance form consists of the following areas: the title area, the vehicle number counter area, the text boxes area, the page frame area, the vehicle image area, the combo box area, and the command buttons areas.

There are two pages in the page frame area. The first page contains a grid that is used to display the corresponding overall vehicle records according to the conditions assigned to the selected command button. The second page contains a grid too. But this grid is used to state the historical logistic records of a specified vehicle that is chosen from the grid of the first page.

The text boxes area displays the overall information concerning about the specified vehicle chosen from the first page grid.

The combo box area is used to set up the following searching conditions about the end-user, the supervisor, and the vehicle category.

The command buttons are used to command the management information system to execute editing, searching, sorting, report printing and etc.

The form dedicated for vehicle searching, as shown in Fig. 3, is a simplified version of the database maintenance form. The editing functions are reserved in the vehicle searching form.

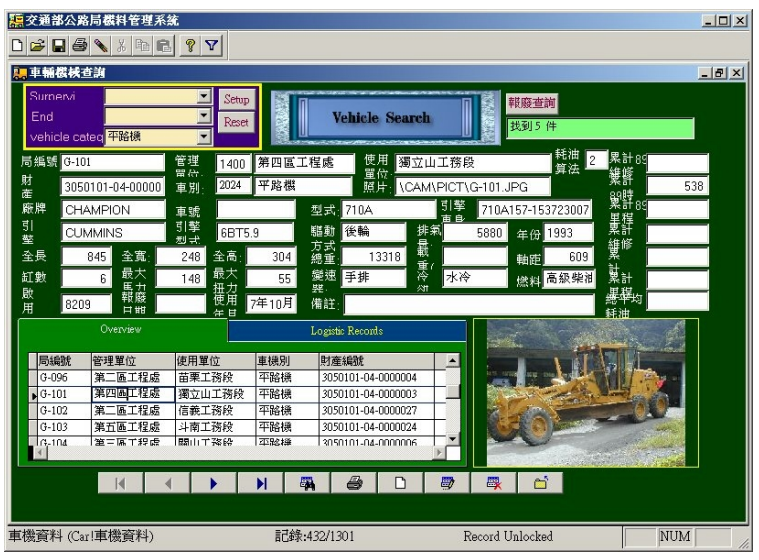

Fig. 3 Vehicle Searching Form

The form for vehicle supervision, as shown in Fig. 4, is used to supervise the performance of the vehicles. The information that will be helpful for the judgments of the vehicle performance is provided in this form.

The information provided by this form is closely related to the information stated in the logistic records. Based on the fundamental logistic records, the value-added information such as the various average values of the maintenance cost, the fuel consumption, the mileage, and the service hours can be calculated and sorted automatically.

Like the database maintenance form, the vehicle supervising form consists of the same areas: the title area, the counter area, the text boxes area, the page frame area, the vehicle image area, the combo box area, and the command buttons area.

But, the page frame area in the vehicle supervising form consists of five pages, instead of two only. Each page contains one grid. The five grids, with each one in its corresponding page, display the sorted vehicles according to the maintenance cost, the fuel consumption, the mileage, the service hours, and the year of manufacturing of 
the vehicle.

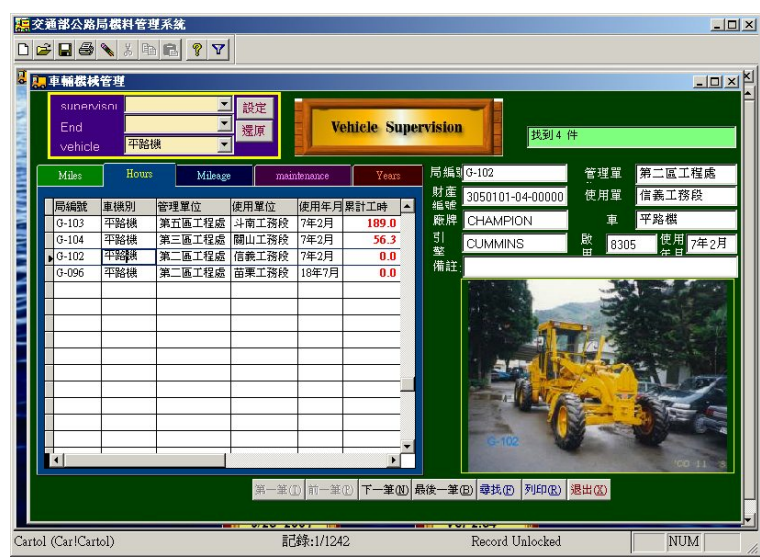

Fig. 4 Form for Vehicle Supervision

By using the logistic record page in the vehicle searching form, as shown in Fig. 3, the logistic records can be searched. In order to keep the logistic records always updated, we implement the forms, as shown in Fig. 5 and Fig. 6 to make the updating work as convenient as possible.

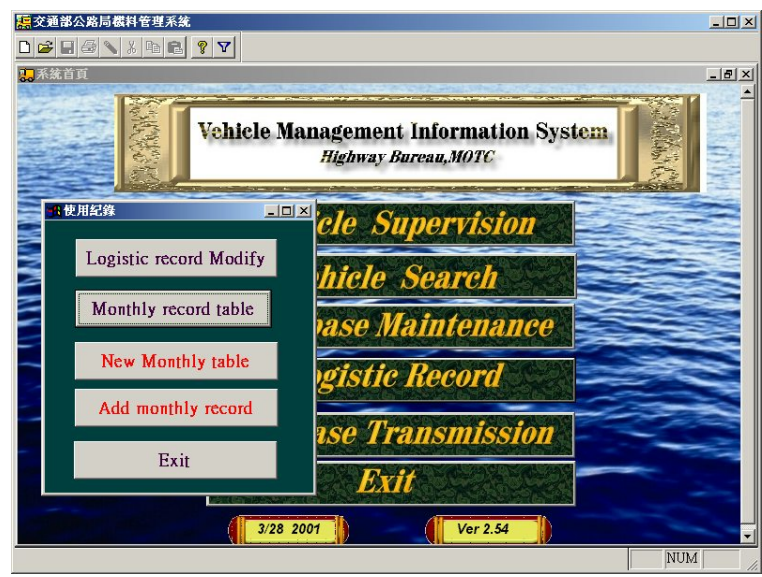

Fig. 5 Menu for Logistics

Fig. 5 shows the menu for handling the logistic records. By selecting the logistic record button in the system menu, as shown in Fig. 1, the menu for logistics will be shown, as in Fig. 5.

For explanation purpose, as an example, Fig. 6 shows a form for record editing and searching after we hit the first button of the menu for logistics.

Once the editing work has been completed, the updated logistic information will automatically incorporated into the related forms, such as database maintenance form and vehicle searching form, as already shown in Fig. 2 and Fig. 3.

The other forms for the corresponding logistic purposes can be similarly designed and implemented based on the requirements and strategies.

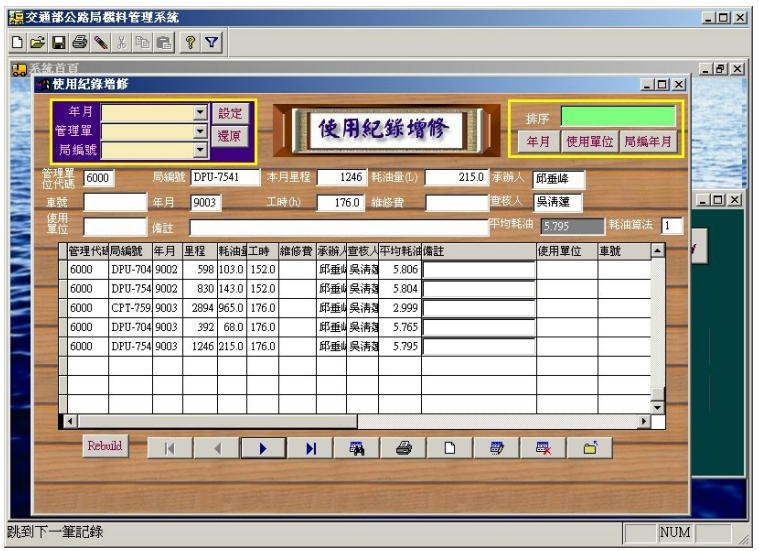

Fig. 6 Form for handling Logistic Records

According to the requirements, the reports of the logistic records can be available for different versions, e.g. excel, html, etc. A report is shown in Fig. 7 for your references.

\begin{tabular}{|c|c|c|c|c|c|}
\hline \multicolumn{4}{|l|}{ 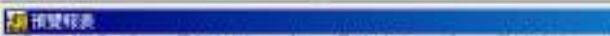 } & \multicolumn{2}{|l|}{$E[a|x|$} \\
\hline 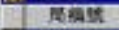 & 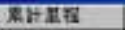 & 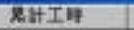 & 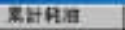 & 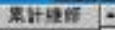 & $=$ \\
\hline V. CEU 7173 & 185570 & 00 & 387130 & 150600 & \\
\hline DFU-75\&3 & 147703 & प0 & 294480 & 400000 & \\
\hline DeY-7352 & 142933 & 0.0 & $2667<0$ & 110350 & \\
\hline DAU-7350 & 113275 & 00 & 19506.0 & 141800 & \\
\hline OPU.73\% & $969+2$ & 00 & 16728.0 & 82220 & \\
\hline DeU.7351 & 92364 & 00 & 164010 & 75000 & \\
\hline DPU:745 & 68505 & 00 & 100730 & 110060 & \\
\hline DEU-7518 & 44172 & n0 & 76830 & 82200 & \\
\hline DFU-761? & 17675 & 00 & 5530.0 & 30300 & \\
\hline DPU-7625 & 14178 & 00 & 2862.0 & 45009 & \\
\hline & & & & & \\
\hline & & & & & \\
\hline & & & & & -1 \\
\hline & & & & & \\
\hline & & & & &. \\
\hline 1.1 & & & & & T \\
\hline
\end{tabular}

Fig. 7 Logistic Report

\subsection{Database transmission}

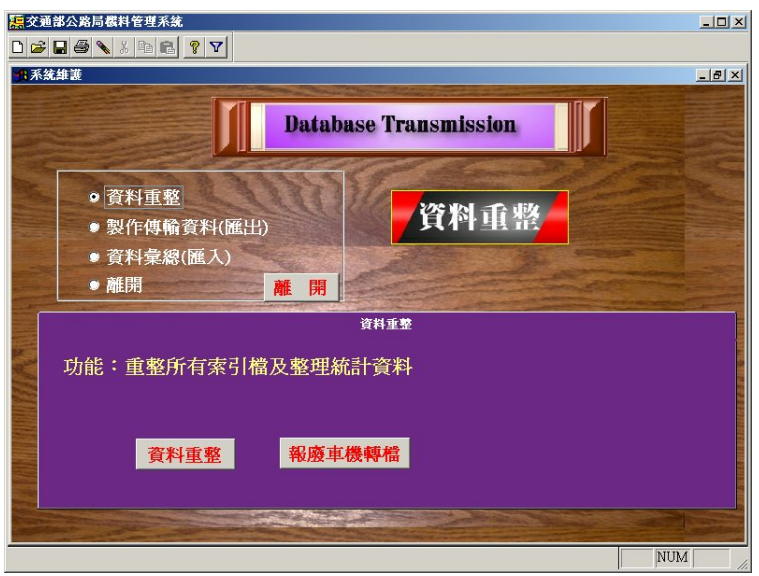

Fig. 8 Form for database Transmission

To keep the database of this management information system always updated, the Internet mechanism is adopted as the database transmission environment. All the updated vehicle files are 
transmitted from the various engineering divisions allocated allover this country to Taiwan Highway Bureau located in Taipei.

A form, as shown in Fig. 8, has been designed to fulfill the database transmission requirement. It offers the following functions: database update, database backup, database integration and database transmission.

\subsection{Photographic zoom out/in technique}

The photographic zoom-out and zoom-in technique has been incorporated into this management information system to make the vehicle identification more easily.

To zoom out or zoom in the vehicle photograph, what we have to do is only a single clicking over the vehicle photograph.

Fig. 9 shows a form with its vehicle photograph being zoomed out.

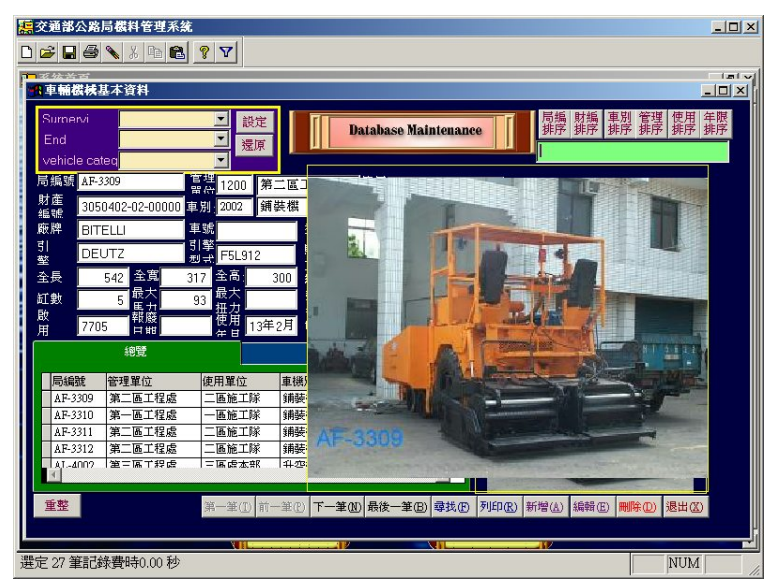

Fig. 9 Zoom-out Effect

\section{CONCLUSIONS}

An Internet-based management information system for the logistics of highway construction and maintenance vehicles has been designed and implemented by Microsoft Visual FoxPro. This system has been used in Taiwan Highway Bureau since last year. It is shown that this system is so useful not only for the logistics and supervision of the 1400 construction and maintenance vehicles owned by Taiwan Highway Bureau, but also helpful for the prevention of scandal intentions and activities.

For the future research, by integrating the advanced logistic strategies into this system, we should be able to make the presented system more intelligent.
The authors would like to thank all the colleagues who are responsible for the logistics and supervision of the highway construction and maintenance vehicles. We also like to say thank you to the colleagues who get involved with the system database maintenance. Without their cooperation, we may not possible to have this job done.

\section{REFERENCES}

[1] Microsoft Co., Visual FoxPro User's Reference Manual, $6^{\text {th }}$ Edition, 2000.

[2] Liang, Y., Shih, F. Y., and Wu, C. H., "A Management Information System for the Supervision of Highway Construction Projects", $17^{\text {th }}$ International Symposium on Automation and Robotics in Construction Proc., Taipei, pp. 10711076, 2000.

[3] Liang, Y., Shih, F. Y., and Wu, C. H., "A Integrated System Design for the Management of Construction Projects and Construction Information Communication", Civil and Hydraulic Engineering, Vol.27, No.3, pp.63-69, Nov. 2000.

[4] Laudon, K. C. and Laudon, J. P., Management Information System, $6^{\text {th }}$ Edition, Prentice Hall, 2000

\section{Acknowledgements}

